\title{
Hacer ejercicio disminuye el riesgo de colecistectomía en mujeres
}

Recreational physical activity and the risk of cholecystectomy in woman. Leitzman MF, Rimm EB, Willaet WC et al. N Engl J Med 1999;341:1777-84

\section{Objetivo}

Evaluar la relación entre la actividad física recreativa (como el trote, o el ciclismo) y el riesgo de colecistectomía.

\section{Diseño}

Estudio de cohortes prospectivo* (Nurses Health Study). Diez años de seguimiento.

Lugar
EE.UU.

\section{Pacientes}

Se incluyeron en el estudio 60290 enfermeras de 40 a 65 años al inicio del estudio (1986), sin historia previa de litiasis biliar.

\section{Evaluación de los factores pronósticos}

Todas las variables fueron evaluadas a través de cuestionarios postales enviados cada dos años. Se midió la actividad física recreàtiva en promedio de horas por semana dedicadas a las distintas actividades como trotar, correr, nadar, aerobics, ciclismo, caminatas, etc. (se excluyó la actividad doméstica y la ocupacional). La suma de todas las actividades arrojaba un puntaje de actividad física semanal (expresado en MET, o equivalentes metabólicos). También se clasificaron las actividades como vigorosas ( 6 o más MET) o no vigorosas (menos de 6 MET). También se evaluaron la inactividad y las horas de televisión semanales.

\section{Medición de resultados principales}

Riesgo relativo ajustado de colecistectomía según nivel de actividad física recreativa. Las variables que se tuvieron en cuenta en el análisis multivariable* fueron la edad, paridad, uso de anticonceptivos orales, reemplazo hormonal, diabetes, tabaquismo, uso drogas hipolipemiantes o tiazidas, antinflamatorios no esteroides, ingesta de fibras, carbohidratos, alcohol y café.

\section{Resultados principales}

Durante los 555381 personas/año de seguimiento ocurrieron 3257 colecistectomías (5\% de la cohorte). La actividad física se asoció inversamente al riesgo de colecistectomía. Las mujeres del quintilo* superior en relación al inferior tuvieron un RR de 0.69 (IC 95\% 0.61 a 0.78). Esta asociación se atenuaba levemente al ajustar por índice de masa corporal, lo que sugiere que el efecto de la actividad física no es mediado solo por su efecto en el peso.

\begin{tabular}{|c|c|c|c|c|c|c|}
\hline Variable & & eactividad físi & ca (MET-hs/se & nana) & & $p$ \\
\hline & $0-1.6$ & $1.7-4.5$ & $4.6-10.5$ & $10.6-22$ & +22.1 & \\
\hline Colecistectomías & 671 & 785 & 687 & 592 & 522 & \\
\hline Personas/año & 95590 & 121651 & 113227 & 112357 & 110556 & \\
\hline RR ajustado (IC 95\%) & 1.0 & $\begin{array}{c}0.92 \\
(0.83-1.02)\end{array}$ & $\begin{array}{c}0.87 \\
(0.78-0.97)\end{array}$ & $\begin{array}{c}0.76 \\
(0.67-0.85)\end{array}$ & $\begin{array}{c}0.69 \\
(0.61-0.78)\end{array}$ & $<0.001$ \\
\hline
\end{tabular}

El riesgo de colecistectomía fue reducido tanto por la actividad física vigorosa como por la no vigorosa. El sedentarismo se asoció positivamente con la colecistectomía.

\section{Conclusiones}

La actividad física recreativa se asoció con una reducción del riesgo de colecistectomía. Esta asociación fue independiente de otros factores de riesgo para litiasis biliar como la obesidad o la pérdida de peso reciente.

\section{COMENTARIO}

El presente estudio, otro producto más del ya prolífico estudio de las enfermeras, agrega otro aporte a los numerosos aportes previos. Es una muestra de cómo un estudio bien diseñado; con una población que responde persistentemente a los cuestionarios enviados por correo cada dos años; y con relativo bajo costo (en ningún momento se ve a las pacientes sino que está todo sustentado en el autoreporte de las mismas); puede seguir nutriendo a la comunidad médica y de pacientes con datos de utilidad. En esta oportunidad los autores se proponen evaluar la relación causal entre la actividad física y la litiasis biliar. En realidad les interesa particularmente la etiología de las litiasis más comunes que son las de colesterol (75\% de las totales). Aunque esta asociación ya fue evaluada prospectivamente en hombres, $1-2$ no existían hasta la fecha datos de estudios prospectivos en mujeres. La debilidad de este estudio, como en todos los estudios observacionales, es que las mujeres no fueron aleatorizadas a distintos niveles de ejercicio, y las mujeres de cada estrato de ejercicio diferían en muchas variables. De todas maneras, en el análisis se evalua en detalle el rol de estas variables potencialmente confundidoras ${ }^{*}$ como la obesidad, edad, cambio de peso reciente, sin modificar las conclusiones.

Es interesante que solo dos o tres horas de actividad recreativa semanal reducen el riesgo de colecistectomía un 20\%, y que con caminatas a buen paso también se observa este efecto.

La litiasis biliar es una causa muy frecuente de cirugía. Otros factores de riesgo potencialmente modificables para prevenir esta entidad son la obesidad, y la brusca pérdida de peso. Es por ello que el consejo a dar en las personas que quieran reducir su riesgo de litiasis sería el de lograr y mantener un peso adecuado, sin fluctuaciones frecuentes del mismo. De requerir descenso de peso, este debería ser gradual, a un ritmo de no más de $1.5 \mathrm{Kg}$ semanal. ${ }^{3}$ Con el aporte de este y otros estudios sabemos ahora que también la actividad física recreativa ayuda a este fin. Este es un efecto benéfico más de los tantos y tan buenos atribuidos a la actividad física.

*Ver glosario

\section{Referencias}

1. Kato I, Nomura A, Stemmermann GN y col. Prospective study of clinical gallbladder disease and its association with obesity, physical activity, and other factors. Dig Dis Sci 1992;37:784-90

2. Leitzman MF, Giovanucci EL, Rimm EB y col. The relation of physical activity to risk of symptomatic gallstone disease in men. Ann Int Med 1998;128:417-25

3. Vega KJ, Johnston DE. Exercise and the gallbladder. N Engl J Med 1999;341:836-837 